\title{
Optimasi Kapasitas Produksi dengan Pendekatan Sistem Antrian (Studi Kasus CV. Sispra Jaya Logam)
}

\author{
St Nova Meirizha, Faradila Ananda Yul, Julian Prayuda \\ Program Studi Teknik Industri Fakultas Teknik Universitas Muhammadiyah Riau \\ Jalan Tuanku Tambusai Ujung Pekanbaru \\ E-mail : nomei_rizha@yahoo.co.id
}

\begin{abstract}
Abstrak
$C V$. Sispra Jaya Logam adalah sebuah perusahaan yang bergerak di bidang industry manufaktur pengecoran logam. Perusahaan ini memproduksi berbagai kebutuhan perusahaan industri seperti roda gigi, gibol joint, greacer, dan lain-lain. Salah satu penyebab antrian pada CV. Sispra Jaya Logam adalah ketidakseimbangan kebutuhan kapasitas dengan ketersediaan kapasitas di lantai produksi. Hal ini disebabkan oleh adanya kekurangan dan kelebihan material yang akan diproses khususnya pada mesin bubut, dimana jumlah produksi yang direncanakan tidak sesuai dengan kapasitas yang tersedia. Rough Cut Capacity Planning (RCCP) merupakan metode yang digunakan untuk mengukur kapasitas stasiun kerja sehingga dapat diketahui apakah suatu jadwal produksi dapat memenuhi permintaan tepat waktu. Berdasarkan proses produksi terlihat banyaknya antrian di stasiun kerja pembubutan. Penelitian terhadap antrian pada proses produksi di CV. Sispra Jaya Logam dilakukan dengan metode RCCP dan model antrian. Langkah pertama dalam perhitungan RCCP adalah perhitungan kapasitas tersedia, setelah itu dilakukan perhitungan kapasitas yang dibutuhkan. Kemudian dilakukan verifikasi kapasitas. Untuk stasiun kerja yang kekurangan kapasitas maka dilakukan penyeimbangan kapasitas dengan pendekatan model antrian. Pendekatan model antrian meliputi uji distribusi, perhitungan antrian pada kondisi sekarang dan perhitungan antrian pada kondisi usulan. Dari implementasi metode diperoleh usulan terbaik adalah dengan menambahkan satu server (mesin) pada stasiun kerja pembubutan. Dari penambahan satu server tersebut diperoleh jumlah unit rata-rata yang menunggu dalam antrian sebesar 0,199 dan waktu menunggu rata-rata dalam antrian adalah 0,232 menit.
\end{abstract}

Kata kunci : Kapasitas Produksi, MPS, RCCP, Teori antrian

\section{Pendahuluan}

\subsection{Latar Belakang}

Semakin berkembangnya dunia industri saat ini membuat para pelaku industri harus melakukan berbagai hal agar tetap bisa bertahan dalam ketatnya persaingan. Perusahaan manufaktur selalu berusaha untuk meningkatkan terus menerus hasil produksinya dan memperbaiki dalam bentuk kualitas, harga, jumlah produksi, pengiriman tepat waktu. Salah satu usahanya adalah dengan mengurangi pemborosan yang tidak mempunyai nilai tambah dalam berbagai hal termasuk penyediaan bahan baku, lalu lintas bahan, pergerakan operator, pergerakan alat dan mesin. Ide utamanya adalah pencapaian secara menyeluruh efisiensi produksi dengan mengurangi pemborosan (waste) yang pada akhirnya adalah meningkatkan daya saing. Antrian yang sangat panjang dan terlalu lama dalam proses produksi merupakan suatu bentuk wasting time sehingga harus diminimasi.

CV.Sispra Jaya Logam merupakan perusahaan manufaktur yang bergerak dalam proses produksi pemesinan di mana perusahan tersebut menghasilkan produk seperti velg roda mobil,gibol join (penyambung pipa miyak) dan perlengkapan suku cadang perkebunan sawit.Akan tetapi dalam pembuatan produk tersebut masih adanya aktivitas waiting (menunggu) pada proses produksi khususnya pada mesin bubut, seperti yang terlihat pada gambar 1. Dengan adanya antrian tersebut maka proses produksi pada mesin berikutnya menjadi terhambat, sehingga banyak waktu yang terbuang untuk proses produksi selanjutnya.

Salah satu penyebab antrian pada Cv.Sispra Jaya Logam yaitu karena ketidakseimbangan kebutuhan kapasitas dengan ketersediaan kapasitas di lantai produksi,hal ini disebabkan oleh adanya kekurangan dan kelebihan material yang akan diproses khususnya padamesin bubut. Dimana 
jumlah produksi yang direncanakan tidak sesuai dengan kapasitas yang tersedia, dan perencana tidak pernah melakukan uji kelayakan terhadap rencana produksi. Oleh karena itu perlu dilakukan uji validasi MPS untuk mengetahui apakah kapasitas yang tersedia di perusahaan dapat memenuhi kapasitas yang dibutuhkan. Jika terjadi kekurangan kapasitas maka perlu dilakukan penambahan kapasitas yang salah satu cara dilakukannya dengan analisis teori antrian.

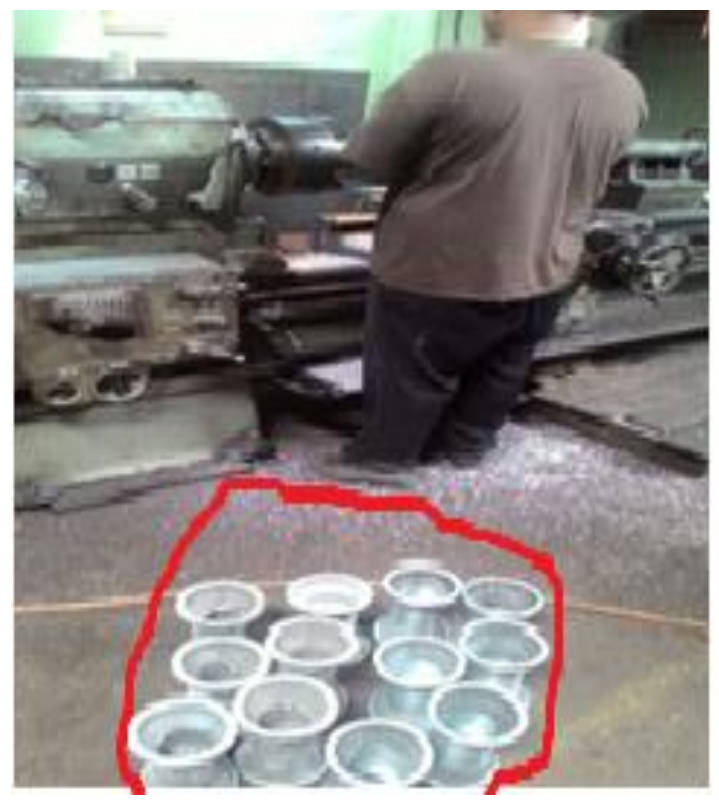

Gambar 1. Antrian pada Mesin Bubut Sumber : CV.Sispra Jaya Logam, 2016

\subsection{Tinjauan Pustaka}

\section{A. Pengertian Kapasitas}

Menurut Blackstone (1989), kapasitas merupakan sebagai jumlah output maksimum yang dapat dihasilkan suatu fasilitas produksi dalamsuatu selang waktu tertentu. Kapasitas merupakan suatu tingkat keluaran dalam periode tertentu dan merupakan kuantitas keluaran tertinggi yang mungkin selama periode itu.Kapasitas dapat disesuaikan dengan tingkat penjualan yang sedang berfluktuasi yang dicerminkan dalam jadwal induk produksi (master production schedule/MPS).

Teori tentang kapasitas menurut Rangkuti (2005) adalah tingkat kemampuan berproduksi secara optimum dari sebuah fasilitas biasanya dinyatakan sebagai jumlah output pada satu periode waktu tertentu.Manajer operasional memperhatikan kapasitas sebaga berikut :

1. Mereka ingin mencukupi kapasitas untuk memenuhi permintaan konsumen.

2. Kapasitas mempengaruhi efisiensi biaya operasional.
3. Kapasitas sangat bermanfaat mengetahui perencanaan output,biaya pemeliharaan kapasitas,dan sangat menentukan dalam analisis kebutuhan investasi.

\section{B. Perancanaan Kebutuhan Kapasitas}

Agar dapat menyesuaikan tingkat kebutuhan kapasitas untuk menanggapi naik turunnya permintaan pasar, perlu dilakukanforecast penjualan dan merencanakan perubahan-perubahan cenderung terjadi tiba-tiba dan drastic, sehingga akan lebih memakan waktu.

Rough Cut Capacity Planning (RCCP) menentukan tingkat kecukupan sumber daya yang direncanakan untuk melaksanakan MPS. RCCP menggunakan definisi dari unit product loads yang disebut sebagai: profil produk-beban (product-load profiles, bills of capacity, bills of resources, atau bill of labor). Penggandaan beban per unit dengan kuantitas produk yang dijadwalkan per periode waktu akan memberikan beban total per periode waktu untuk setiap pusat kerja (work center). RCCP lebih terperinci dari RRP, karena RCCP menghitung beban untuk semua item yang dijadwalkan dan dalam periode waktu aktual. Apabila proses RCCP mengindikasikan bahwa MPS adalah layak, MPS akan diteruskan ke proses MRP guna menentukan bahan baku atau material, komponen, dan subassemblies yang dibutuhkan.

Pada dasarnya terdapat empat langkah yang diperlukan untuk melaksanakan RCCP, yaitu:

1. Memperoleh informasi tentang rencana produksi dari MPS.

2. Memperoleh informasi tentang struktur produk dan waktu tunggu (lead times).

3. Menentukan bill of resources.

4. Menghitung kebutuhan sumber daya spesifik dan membuat laporan RCCP.

Ada 3 teknik untuk merubah kuantitas MPS dari unit yang diproduksi menjadi jumlah waktu yang diperlukan untuk sumber daya tertentu, yaitu:

\section{Capacity Planning Using Overall Factor (CPOF)}

Perencanaan Kapasitas dengan Menggunakan Semua Faktor. Karakteristiknya:

a. Membutuhkan tiga input: MPS, total waktu yang diperlukan untuk membuat sebuah produk (Ws), waktu yang diperlukan untuk membuat sebuah produk pada tiap sumber daya/departemen/work center.

b. Membutuhkan data yang tidak terlalu detil dan proses perhitungan paling mudah.

Perhitungan kebutuhan sumber daya dengan $\mathrm{CPOF}$ dilakukan dengan cara:

1. Hitung alokasi waktu mesin untuk sebuah produk (atau komponen) pada setiap mesin, lalu hitung total waktunya. 
2. Hitung proporsi waktu proses untuk setiap mesin.

3. Tentukan nilai waktu yang dibutuhkan untuk mengerjakan produk/ komponen sesuai dengan jumlah rencana produksi (MPS)

4. Tentukan nilai waktu pada masing-masing mesin berdasarkan proporsi waktu prosesnya.

5. Hitung kapasitas waktu tersedia yang mungkin untuk setiap mesin (pertimbangkan, maintenance, libur, dll)

6. Buat grafik, lalu cek apakah seluruh periode (bulan) nilai waktu (poin 4) semuanya dibawah kapasitas tersedia (poin 5), jika ya, maka MPS valid, jika tidak MPS perlu direvisi.

II. Bill of Labor (BOLA)

Bill of labor: daftar jumlah tenaga kerja/waktu yang dibutuhkan untuk membuat sebuah item. Pada metode ini dibutuhkan input MPS dan waktu standar dari tiap sumber yang dinyatakan dalam bentuk Bill of Labor. Dimana waktu standar adalah waktu yang dibutuhkan rata-rata pekerja untuk memproduksi 1 unit pada kondisi normal (sudah mempertimbangkan allowance).

Perhitungan kebutuhan kapasitas dilakukan dengan cara mengalikan jumlah kuantitas pada MPS dengan waktu yang diperlukan tiap sumber daya/work center pada Bill of Labor.

\section{Resource Profile}

Resource Profile membagi kebutuhan tenaga kerja berdasarkan waktu. Tiap Bill Of Labor harus dipecah berdasarkan waktu jika menggunakan pendekatan ini.

\section{Teori Antrian}

Teori tentang antrian diketemukan dan dikembangkan oleh A.nK.Erlang, seorang insinyur dari Denmark yang bekerja pada perusahaan telefon di Kopenhagen pada tahun 1910. Model antrian membantu para manajer untuk membuat keputusan dengan cara menganalisis antrian sehingga dapat diperoleh banyak ukuran kinerja sebuah antrian, meliputi hal berikut:

1. Waktu rata-rata yang dihabiskan oleh pelanggan dalam antrian.

2. Waktu rata-rata yang dihabiskan oleh pelanggan dalam sistem (waktu tunggu ditambah waktu pelayanan).

3. Jumlah pelanggan rata-rata dalam sistem.

4. Probabilitas fasilitas pelayanan akan kosong.

5. Faktor utilisasi sistem.

6. Probabilitas sejumlah pelanggan berada dalam sistem.

Terminologi dan notasi yang digunakan dalam teori antrian adalah sebagai berikut:

1. En: Keadaan dimana ada $n$ calling unit pada sistem antrian.
2. Pn ( $\mathrm{t})$ :Kemungkinan bahwa ada tepat $\mathrm{n}$ calling unit pada

3. SA pada saat $t$.

4. S: Jumlah pelayan (untuk saluran pelayanan paralel) pada SA.

5. $\lambda_{n}$ : Tingkat kedatangan rata-rata (ekspektasi jumlah kedatangan per satuan waktu) dari calling unit baru jika ada $n$ unit dalam system.

6. $\mu_{\mathrm{n}}$ : Tingkat pelayanan rata-rata (ekspektasi jumlah unit yang dapat selesai dilayani per satuan waktu) jika ada $n$ unit dalam system.

7. $\rho=\lambda / s \mu$ : faktor penggunaan (utilisasi )untuk fasilitas pelayanan yaitu ekspektasi perbandingan dari waktu sibuk para pelayan.

8. Pn : Kemungkinan bahwa ada tepat $\mathrm{n}$ calling unit dalam SA.

9. L : Ekspektasi jumlah pelanggan dalam system.

10.Lq : Ekspektasi panjang antrian.

11.W : Ekspektasi waktu menunggu dalam system.

12. Wq :Ekspektasi waktu menunggu dalam antrian (tidak termasuk waktu pelayanan).

Berdasarkan asumsi model M/M/1 diperoleh persamaan sebagai berikut:

1. Po $=1-\frac{\lambda}{\mu} \rightarrow$ Peluang tidak ada pelanggan dalam sistem.

2. Pn $=\left(\frac{\lambda}{\mu}\right)^{2}\left(1-\frac{\lambda}{\mu}\right) \rightarrow$ peluang $n$ pelanggan dalam sistem

3. $\mathrm{L}=\left(\frac{\lambda}{\mu-\lambda}\right) \rightarrow$ Rata-rata pelanggan yang diharapkan.

4. $\mathrm{Lq}=\frac{\lambda^{2}}{\mu(\mu-\lambda)} \rightarrow$ Rata-rata pelanggan yang diharapkan dalam antrian.

5. $\mathrm{W}=\frac{1}{\mu-\lambda} \rightarrow$ Waktu yang diharapkan oleh pelanggan selama dalam sistem.

6. Wq $\frac{\lambda}{\mu(\mu-\lambda)} \rightarrow$ Waktu yang diharapkan oleh pelanggan selama menunggu dalam antrian.

7. $\mathrm{U}=\lambda / \mu \rightarrow$ Tingkat intensitas fasilitas pelayanan(prob.pelayanan sedang sibuk.

8. $\mathrm{I}=1-\mathrm{U} \rightarrow$ Prob.pelayanan tidak sibuk (idle time).

\section{Methodologi}

Tahapan metodologi dalam penelitian ini dapat dilihat pada gambar 2 berikut ini : 


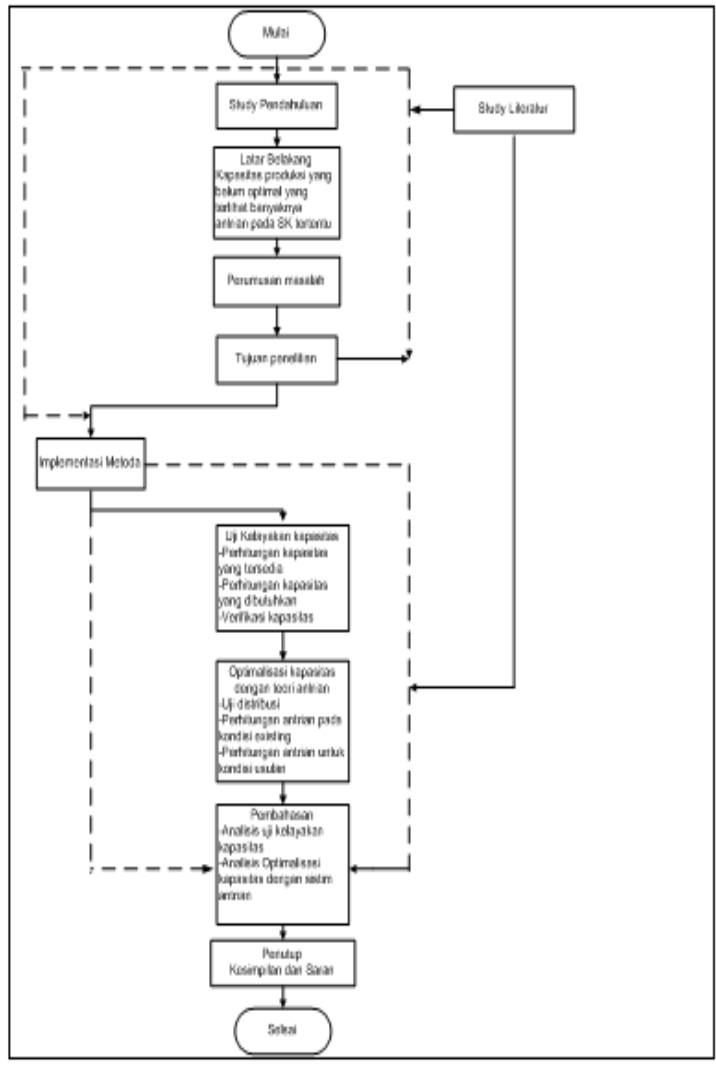

Gambar 2. Metodologi Penelitian

\section{Hasil dan Pembahasan}

Ada beberapa tahapan yang dilakukan dalam implementasi metode pada penelitian ini.

\subsection{Uji Kelayakan Kapasitas}

Kapasitas produksi yang kecil menjadi batu sandungan bagi perusahaan untuk memenuhi permintaan yang ada terbukti dari banyaknya antrian yang terjadi pada proses produksi yang dapat dilihat pada data yang akan di bahas dalam teori antrian. Dengan adanya antrian menyebabkan konsumen kadang-kadang merasa kesal sehingga ada beberapa konsumen yang terkadang membatalkan pesanannya ke pabrik. Hal ini dirasa sangat merugikan sekaligus menjadi kelemahan perusahaan.

\subsubsection{Perhitungan Kapasitas Tersedia}

Menurut Blackstone (1989), kapasitas merupakan sebagai jumlah output maksimum yangdapat dihasilkan suatu fasilitas produksi dalamsuatu selang waktu tertentu.Perhitungan kapasitas tersedia dapat dilihat pada tabel berikut:

Tabel 1.

Kapasitas Tersedia Selama Satu Minggu

\begin{tabular}{lcccccccr}
\hline Stasiun Kerja & Man Power & $\mathrm{S}$ & $\mathrm{H}(\mathrm{Jam})$ & $\mathrm{W}$ & $\mathrm{T}$ & $\mathrm{U}(\%)$ & $\mathrm{E}(\%)$ & $\begin{array}{c}\text { Kapasitas Tersedia } \\
\text { (Jam/Hari) }\end{array}$ \\
\hline Pengecoran & 10 & 1 & 11 & 6 & 660 & 0.87 & 0.91 & 522,5220 \\
Pembongkaran & 6 & 1 & 7 & 6 & 252 & 0.87 & 0.91 & 199,5084 \\
Pengerindaan & 6 & 1 & 7 & 6 & 252 & 0.87 & 0.91 & 199,5084 \\
Pembubutan & 2 & 1 & 7 & 6 & 84 & 0.87 & 0.91 & 66,5028 \\
Finishing & 6 & 1 & 7 & 6 & 252 & 0.87 & 0.91 & 199,5084 \\
\hline
\end{tabular}

Keterangan :

$$
\begin{aligned}
\mathrm{S} & =\text { Shif Kerja } \\
\mathrm{KT} & =\text { Kapasitas Tersedia } \\
\mathrm{H} & =\text { Jam Kerja } \\
\mathrm{W} & =\text { Hari Kerja } \\
\mathrm{E} & =\text { Efisiensi } \\
\mathrm{T} & =\text { Total dari Man Power x S x H x W } \\
\mathrm{U} & =\text { Utilitas }
\end{aligned}
$$

\subsubsection{Perhitungan Kapasitas yang Dibutuhkan}

Pengolahan data RCCP dengan menggunakan metode Capacity Planning using Overall Factors (CPOF) ini membutuhkan data berupa proporsi historis yang merupakan sebuah persentase waktu pada masing-masing proses terhadap waktu proses secara keseluruhan pada pembubutan greacer.Nilai proporsi historis didapat dari waktu yang digunakan pada setiap proses pada produksi greacer yang sudah distandarkan. Dan waktu standar tersebut dari menit diubah menjadi jam. Selanjutnya total waktu proses dalam jam digunakan sebagai pembagi didalam masing-masing prosessehingga didapatlah nilai PH (proporsi historis) pada setiap proses yang dilakukanwaktu proses.

Untuk contoh perhitungan kapasitas yang dibutuhkan adalah sebagai berikut:

$$
\mathrm{PH}=\frac{W P}{W P t}
$$

Dimana :

$\mathrm{PH}=$ Proporsi Histori 
WP $=$ Waktu Proses

WPT $=$ Total Waktu Proses

Tabel 2.

Waktu Proses Dan Proporsi Histori

\begin{tabular}{llccc}
\hline WC & Stasiun Kerja & $\begin{array}{c}\text { Waktu } \\
\text { Proses } \\
\text { (menit) }\end{array}$ & Jam & PH \\
\hline 1 & Pengecoran & 4,4 & 0,07 & 0,036 \\
2 & Pembongkaran & 1,2 & 0,07 & 0,010 \\
3 & Penggerindaan & 25 & 0,41 & 0,214 \\
4 & Pembubutan & 60 & 1 & 0,523 \\
5 & Finishing & 25 & 0,41 & 0,214 \\
& Total & & 1,91 & \\
\hline
\end{tabular}

Dari proporsi historis kemudian dihitung kapasitas yang dibutuhkan sebagai berikut:
A) $\mathrm{KB}$ (ming)COR = PHcor $\mathrm{x}$ KBming $=0.036 \mathrm{x} 286.5 \mathrm{jam}$$$
=10.314 \mathrm{jam}
$$
B) $\mathrm{KB}$ (ming)PEM = PHpem $\mathrm{x}$ KBming $=0.010 \times 286.5 \mathrm{jam}$$$
=2.865 \mathrm{jam}
$$
C) $\mathrm{KB}$ (ming)PENG $=$ PHpeng $\mathrm{x}$ KBming $=0.214 \times 286.5 \mathrm{jam}$$$
=61.311 \mathrm{jam}
$$
D) $\mathrm{KB}$ (ming) $\mathrm{MB}=\mathrm{PHmb} \times \mathrm{KBming}$ $=0.523 \times 286.5 \mathrm{jam}$$$
=149.8395 \mathrm{jam}
$$
E) $\mathrm{KB}$ (ming)FIN = PHfin $\mathrm{x}$ KBming

$$
\begin{aligned}
& =0.214 \times 286.5 \mathrm{jam} \\
& =61.311 \mathrm{jam}
\end{aligned}
$$

\subsubsection{Verifikasi Kapasitas}

Verifikasi kapasitas dilakukan untuk membandingkan antara kapasitas tersedia dengan kapasitas yang dibutuhkan.

Tabel 3.

Data Rekapitulasi kapasitas 1 minggu

\begin{tabular}{lcr}
\hline Stasiun Kerja & $\begin{array}{c}\text { Kapasitas } \\
\text { Tersedia } \\
\text { (Jam/Hari) }\end{array}$ & $\begin{array}{c}\text { Kapasitas Yang } \\
\text { Dibutuhkan } \\
\text { (Jam/Hari) }\end{array}$ \\
\hline Pengecoran & 522,5220 & 10,3140 \\
Pembongkaran & 199,5084 & 2,8650 \\
Penggerindaan & 199,5084 & 61,3110 \\
Pembubutan & 66,5028 & 149,8395 \\
Finishing & 199,5084 & 61,3300 \\
\hline
\end{tabular}

Dari perbandingan di atas kemudian dilakuakn perhitungan persentase kelebihan kapasitas untuk periode perminggu dengan rumus:

$$
\% \text { kelebihan }=\frac{S P \text { ming }(\text { Cor })}{A C \text { ming }(\text { Cor })}
$$

Perhitungan verifikasi kapasitas selengkapnya dapat dilihat pada tabel 4 .
Tabel 4.

Rekapitulasi persentasi verifikasi kapasitas

\begin{tabular}{lcc}
\hline Stasiun Kerja & Persentase $(\%)$ & Layak/Tidak \\
\hline Pengecoran & 98 & Layak \\
Pembongkaran & 98 & Layak \\
Penggerindaan & 69 & Layak \\
Pembubutan & 1,253 & Tidak Layak \\
Finishing & 69 & Layak \\
\hline
\end{tabular}

Berdasarkan tabel di atas maka didapatlah bahwa pada stasiun kerja pembubutan terjadi kekurangan kapasitas. Oleh sebab itu perlu dilakukan optimalisasi kapasitas dengan pendekatan sistim antrian.

\subsection{Optimalisasi Kapasitas Dengan Teori antrian}

Tahapan yang dilakukan dalam mengoptimalkan kapasitas dengan pendekatan teori antrian meliputi uji distribusi, melakukan perhitungan antrian pada kondisi exsisting, dan perhitungan antrian untuk kondisi usulan.

\subsubsection{Uji Distribusi}

Hasil uji distribusi data hasil pengukuran waktu kedatangan dan waktu pelayanan di setiap stasiun kerja dapat dilihat pada gambar 3 dan gambar 4.

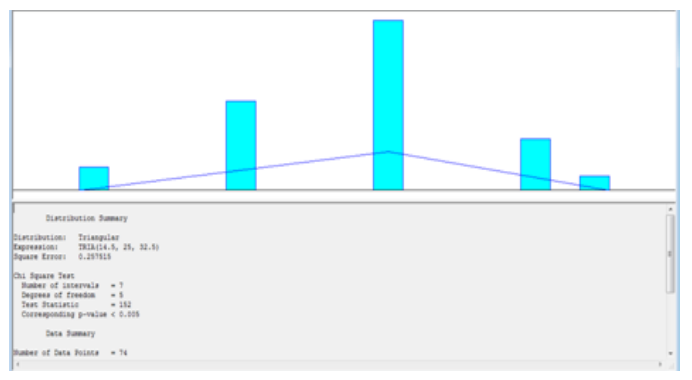

Gambar 3. Grafik distribusi kedatangan (Triangular)

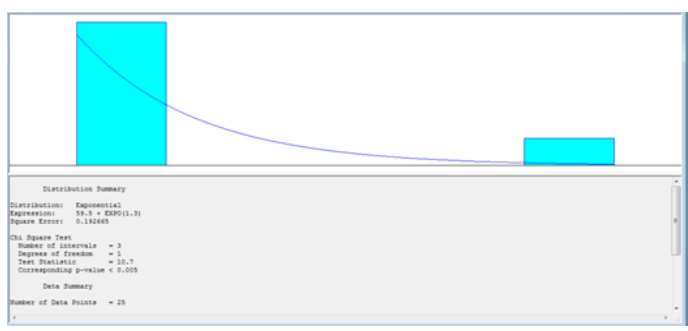

Gambar 4. Grafik waktu pelayanan (Eksponensial)

\subsubsection{Perhitungan antrian pada kondisi existing.}

Analisis antrian menggunakan model antrian yang saat ini diterapkan oleh CV. Sispra Jaya Logam yaitu model antrian jalur tunggal 
(M/M/1) dalam periode tertentu adalah sebagai berikut :

Tabel 5.

Hasil kinerja sistim antrian model M/M/1

\begin{tabular}{cccccc}
\hline \multicolumn{7}{c}{ Kinerja Sistem Antrian } \\
Po & $\mathrm{P}$ & Ls & Lq & Ws & Wq \\
\hline 0,143 & 0,86 & 5,99 & 5,13 & 6,99 & 5,99 \\
\hline
\end{tabular}

Dari Tabel di atas dapat diketahui bahwa :

1. Tingkat utilisasi $(\rho)$, dimana pada jam tersebut tingkat utilisasi kesibukan petugas (operator) sebesar 0,86 atau $86 \%$.

2. Rata-rata jumlah dalam antrian (Lq), dimana rata-rata jumlah produk yang mengantri di dalam antrian sebanyak 5,13 .

3. Rata-rata jumlah produk dalam sistem antrian (Ls), dimana rata-rata jumlah produk yang mengantri di stasiun produksi sebanyak 5,99 pcs.

4. Waktu rata-rata yang dihabiskan suatu produk untuk menunggu dalam antrian (Wq). Waktu yang diperlukan produk dalam antrian pada proses produksi adalah 5,99

5. Waktu rata-rata yang dihabiskan produk dalam sistem (Ws). Waktu yang diperlukan produk dalam sistem pada proses produksi adalah 6,99 .

\subsubsection{Perhitungan antrian pada kondisi Usulan Dengan Model Multiple Channel QuerySystem $(\mathrm{M} / \mathrm{M} / \mathrm{s})$}

Model Multiple Channel Query System (M/M/s) merupakan model antrian dimana terdapat lebih dari satu server (mesin) yang tersedia untuk melayani proses produksi. Untuk mengoptimalkan kinerja serta meningkatkan kepuasan pelanggan dalam hal ini adalah sebaiknya pihak CV.sispra Jaya Logam mempertimbangkan untuk menambahkan server (mesin) pada masing-masing proses produksi agar produk tidak terlalu lama menunggu dalam antrian dan dapat segera dikerjakan, dengan begitu konsumen akan merasa puas dan kinerja petugas produksi akan menjadi optimal.

Tabel 6 adalah analisis antrian dengan model Multiple Channel Query system (M/M/s) pada bagian proses produksi dengan menggunakan data yang telah diproleh pada saat melakukan pengamatan selama masa penelitian.

Dari tabel perbandingan hasil diatas, dapat diketahui bahwa dengan menerapkan sistem antrian dengan menggunakan model yang baru $(\mathrm{M} / \mathrm{M} / \mathrm{s})$ maka kinerja dari sistem antrian akan meningkat dan lebih optimal. Oleh karena itu, pihak CV.Sispra Jaya Logam perlu mempertimbangkan untuk menambah server (mesin) pada proses produksi.Dengan melihat jumlah kedatangan produk dan tingkat antrian yang terjadi setiap harinya. Hal ini perlu dilakukan agar kinerja kerja proses produksi keseluruhan tidak terganggu dan dapat berjalan secara optimal sehingga tidak membuat produk mengantri terlalu lama.Berdasarkan paparan diatas, diketahui bahwa penerapan sistem antrian model jalur berganda $(\mathrm{M} / \mathrm{M} / \mathrm{s})$ pada bagian proses produksi dapat mengoptimalkan proses produksi yang terjadi saat ini.

Tabel 6.

Perbandingan kinerja sistem antrian Kondisi Usulan

\begin{tabular}{lccc}
\hline \multicolumn{1}{c}{ Karakteristik Antrian } & 1 Server & 2 Server & 3 Server \\
\hline Jumlah unit yang menunggu dalam antrian (Lq) & 5,13 & 0,199 & 0,055 \\
Jumlah rata-rata dalam system (Ls) & 5,99 & 1,056 & 0,912 \\
Waktu rata-rata yang dihabiskan unit untuk & 5,99 & 0,232 & 0,064 \\
$\begin{array}{l}\text { menunggu dalam antrian (Wq) } \\
\text { Waktu rata-rata yang dihabiskan dalam antrian atau }\end{array}$ & 6,99 & 1,23 & 1,064 \\
$\begin{array}{l}\text { sedang dilayani (Ws) } \\
\text { Probabilitas fasilitas pelayanan sibuk (Po) }\end{array}$ & 0,143 & 0,4 & 0,465 \\
Tingkat Utilisasi (p) & 0,86 & 0,429 & 0,285 \\
\hline
\end{tabular}

Dari tabel perbandingan hasil diatas, dapat diketahui bahwa dengan menerapkan sistem antrian dengan menggunakan model yang baru $(\mathrm{M} / \mathrm{M} / \mathrm{s})$ maka kinerja dari sistem antrian akan meningkat dan lebih optimal. Oleh karena itu, pihak CV.Sispra Jaya Logam perlu mempertimbangkan untuk menambah server (mesin)pada proses produksi.Dengan melihat jumlah kedatangan produk dan tingkat antrian yang terjadi setiap harinya. Hal ini perlu dilakukan agar kinerja kerja proses produksi keseluruhan tidak terganggu dan dapat berjalan secara optimal sehingga tidak membuat produk mengantri terlalu lama.Berdasarkan paparan diatas, diketahui bahwa penerapan sistem antrian model jalur berganda (M/M/s) pada bagian proses produksi dapat mengoptimalkan proses produksi yang terjadi saat ini. 


\section{Simpulan}

Berdasarkan hasil pengolahan data dan pembahasan yang telah dikemukakan pada bab sebelumnya, dapat diambil beberapa kesimpulan sebagai berikut :

1. Dari uji kelayakan kapasitas produksi pada setiap stasiun kerja dapat dilihat bahwa pada empat stasiun kerja tidak terjadi kekurangan kapasitas yaitu stasiun kerja pengecoran, pembongkaran, penggerindaan, dan finishing. Kekurangan kapasitas hanya terjadi paada stasiun kerja pembubutan sebesar $125.3 \%$, sehingga perlu dilakukan penyeimbangan kapasitas.

2. Penyeimbangan kapasitas dengan model antrian dilakukan dengan mensimulasikan dua dan tiga server pada mesin bubut.Hasil perhitungan dengan 2 server diperoleh jumlah unit yang menunggu (Ls 1,056 dan Lq 0,199)dan juga waktu antrian (Wq 0,232 dan Ws 1,23). Sedangkan dengan perhitungan 3 server diperoleh jumlah unit yang menunggu (Ls 0,912 dan Lq 0,055) dan juga waktu antrian (Wq 0,064 dan Ws 1,064). Dengan perhitungan 2 server sudah menunjukkan angka yang kecil. Nilai tersebut tidak berbeda signifikan untuk tiga server. Oleh karena itu disimpulkan perlu penambahan satu server saja untuk mesin bubut.

\section{Saran}

Berdasarkan hasil penelitian dan pembahasan yang telah dijelaskan pada bab sebelumnya, maka penulis dapat memberikan beberapa saran kepada CV. Sispra Jaya Logam diantaranya adalah :

1. Untuk mengoptimalkan kapasitas produksi pada CV. Sispra Jaya Logam, maka pihak perusahaan perlu mempertimbangkan penambahan 1 mesin (server) khususnya pada proses produksi dimana pada proses produksi tersebut setiap harinya terdapat antrian produk yang cukup panjang pada jam sibuk kerja,

2. Perlu diadakan kajian lebih lanjut dengan menggunakan parameter biayaagar dampak pemilihan skenario model antrian dapat diketahui kondisi yangpaling optimalnya untuk diterapkan oleh perusahaan.

\section{Daftar Pustaka}

[1]. Anaviroh, 2011, Model Antrian Satu Server dengan Pola Kedatangan Berkelompok (Batch Arrival). Skripsi Jurusan Pendidikan Matematika Fakultas Matematika dan Ilmu
Pengetahuan Alam Universitas Negeri Yogyakarta.

[2] Ahmad, D, 2006, Operations Research(Model-Model Pengambilan Keputusan). Sinar Baru Algesindo: Bandung.

[3] Blackstone, 1989, Kapasitas merupakan sebagai jumlah output maksimum yang dapat dihasilkan suatu fasilitas produksi dalam suatu selang waktu tertentu.

[4] Erlang,A, 1917, Solutionof some problems in the Theory of Probabilities of Significance in Automatic.

[5] Levin et al, 2002, Variabel acak adalah suatu variabel yang nilainya bisa berapa saja sebagai hasil daripercobaan acak.

[6] Rangkuti,F, 2005,Tingkat kemampuan produksi secara optimum dari sebuah fasilitas biasanya dinyatakan sebagai jumlah output pada satu periode waktu tertentu dan tahapan-tahapan penyusunan perencanaan kapasitas.

[7] Sumayang,L,2003, Kapasitas adalah tingkat kemampuan produksi dari suatu fasilitas biasanya di nyatakan dalam jumlah volume output per periode waktu. 